\title{
A Study of Surfactant on 100 Preterm and Late Preterm Neonates with Respiratory Distress Syndrome Admitted in Paediatric Department During the Period January 2018 - June 2019
}

\author{
Sujatha Devi Rapaka ${ }^{1}$, Satya Kumari Kunche ${ }^{2}$ \\ 1, 2 Department of Paediatrics, Andhra Medical College, NTR University of Health Sciences, \\ Visakhapatnam, Andhra Pradesh, India.
}

\section{ABSTRACT}

\section{BACKGROUND}

Respiratory distress syndrome (RDS) is a common condition in preterm and late preterm neonates with age less than or equal to 34 weeks or weight $<1.5 \mathrm{kgs}$ need some intervention like intubation, and administration of surfactant. Early administration of surfactant can give better outcome. We wanted to assess the outcome of babies administered with surfactant.

\section{METHODS}

New-born babies with respiratory distress admitted to NICU, Department of Paediatric, King George Hospital, Andhra Medical College, Visakhapatnam, Andhra Pradesh, were enrolled in this case control study. A total of 100 neonates of both sexes who were admitted with respiratory distress syndrome of $<35$ weeks and $<$ $1.5 \mathrm{~kg}$ were included in the study.

\section{RESULTS}

Out of 100 neonates, most of the neonates 34 (66.6\%) in the surfactant group and $37(75.0 \%)$ neonates in the control group were between $30 \mathrm{wks}$ to $32 \mathrm{wks}$ of GA respectively. $12(25.0 \%)$ in the surfactant group and $10(19.4 \%)$ in the control group were between 27 wks. to 29 wks. of GA respectively. Very less $4(11.76 \%)$ in the surfactant group and $3(8.10 \%)$ in the control group were between 32 wks. of GA to 35 weeks respectively.

\section{CONCLUSIONS}

The study concludes that among spontaneously breathing premature infants treated with INSURE, decreases the need for subsequent MV by $22 \%$. The higher birth weight, the use of antenatal steroids, the lower RDS score at the time of procedure and the early use of surfactant are the good predictors in the INSURE success group.

\section{KEY WORDS}

RDS, Preterm, Intubation, Surfactant (INSURE), GA (Gestational age), MV (Mechanical ventilation), Pulmonary Haemorrhage, CPAP.
Corresponding Author: Dr. Sujatha Devi Rapaka, Assistant Professor, Department of Paediatrics, Andhra Medical College, NTR University of Health Sciences, Visakhapatnam, Andhra Pradesh, India E-mail: sujatha12341234@gmail.com

DOI: $10.14260 /$ jemds/2022/35

How to Cite This Article:

Rapaka SD, Kunche SK. A study of surfactant on 100 preterm and late preterm neonates with respiratory distress syndrome admitted in paediatric department during the period January 2018 - June 2019. J Evolution Med Dent Sci 2022;11(01):184-188, DOI: 10.14260/jemds/2022/35

Submission 24-12-2021, Peer Review 30-12-2021, Acceptance 27-01-2022, Published 29-01-2022.

Copyright (C) 2022 Sujatha Devi Rapaka et al. This is an open access article distributed under Creative Commons Attribution License [Attribution 4.0 International (CC BY 4.0)] 


\section{BACKGROUND}

Respiratory distress syndrome, resulting from a deficiency of surfactant is the most frequent clinical respiratory disorder in preterm infants. It is the single most important cause of morbidity and mortality in preterm infants. These Infants with RDS require ventilator support at birth. A treatment goal for neonates ${ }^{1}$ with RDS is to minimize their time spent on ventilator. Prevention of neonatal respiratory distress syndrome by tracheal instillation of surfactant. ${ }^{2} \mathrm{Few}$ days on ventilator means fewer complications such as chronic lung disease and ventilator associated pneumonia. During the past many years, many placebo controlled trials have shown that exogenous surfactant is effective in the treatment of RDS. The need for supplemental oxygen and mechanical ventilation decreases in patients receiving surfactant. The incidence of pneumothorax, and interstitial emphysema is decreased by $50 \%$ to $80 \%$.

Infants requiring prolonged ventilation are also at risk for poor neuro developmental outcome. Minimize the duration of MV may decrease over all length of stay and lower the costs of hospitalization.

Lower the gestational age higher the incidence of RDS, accounting for nearly $80 \%$ incidence in preterm infants with gestational age $<28$ wks. Surfactant deficiency results in lower functional capacity, increase work of breathing and respiratory failure. The increased survival due to the treatment of new-born infants with prophylactic or early selective $^{3}$ surfactant combined with NCPAP in very preterm infant. Surfactant amounts to 3 lives per 10,000 births. If 10 million infants are born in developed countries each year, then an estimated 30,000 lives have been saved in the past 10 years with prophylactic versus selective ${ }^{4}$ use of surfactant in preventing morbidity and mortality in preterm infants, morbidity will be reduced. Pneumothorax and other forms of air leak have become a rarity for infants with respiratory distress syndrome. All current exogenous surfactants reduce the severity of RDS. Most also reduce the mortality rates associated with RDS by $40 \%$ to $60 \%$, and they significantly reduce overall mortality among premature infants at risk for RDS

Mechanical ventilation may induce varying degrees of lung injury with epithelial disruption followed by fluid leakage and inflammatory response that can inactivate surfactant. Multiple versus single dose of exogenous surfactant for the prevention of mechanical ventilation as treatment of neonatal respiratory distress syndrome.

Mechanical ventilation is the single most common risk factor in the development of BPD.

Intratracheal exogenous surfactant replacement therapy reduces mortality by early ${ }^{5}$ extubation and nasal continuous positive airway pressure (NCPAP) ${ }^{6}$ after surfactant treatment for respiratory distress syndrome among preterm infants < 30 weeks' gestation, need for mechanically ventilation (MV) and to prevent the MV induced complications like air leak. With prophylactic or early surfactant therapy being superior to late rescue therapy in reducing mortality and respiratory morbidity.

By maintaining alveolar recruitment early implementation of continuous positive airway pressure (CPAP) by itself, without surfactant therapy, has been shown to improve outcome in infants with RDS. The NCPAP alone in mild to moderate RDS still result in up to $40 \%$ to $60 \%$ of patients requiring $\mathrm{MV}$.

The purpose of the study is to assess the effectiveness of dose of intratracheal surfactant administration during critical phase of RDS followed by rapid extubation and institution of CPAP without MV as a cost - effective treatment. In a study done by verder ${ }^{7}$ et al in 1999 (45) to determine whether early versus late treatment with procaine surfactant (curosurf) reduces the requirement of mechanical ventilation in very preterm infants primarily supported by NCPAP. To determine the outcome in preterm babies with RDS by early administration of surfactant.

\section{METHODS}

New-born babies with respiratory distress admitted to NICU, Department of Paediatrics, King George Hospital, Andhra Medical College, Visakhapatnam were enrolled in this case control study. A total of 100 neonates who came with respiratory distress syndrome (RDS) with $<35$ weeks and < $1.5 \mathrm{~kg}$ were taken in the study including both the sex. The study was conducted from January 2018 to July 2019.

\section{Study Procedure}

Parental informed consent was obtained prior to the procedure. Arterial blood gas analysis was performed before the procedure. Infants with surfactant therapy and NCPAP were taken as (surfactant group) and infants to whom parental consent was not given and who came late to hospital were taken as (non-surfactant group).

\section{Inclusion Criteria}

1. All neonates who are admitted in NICU with features of respiratory distress syndrome with $<35$ weeks and $<1.5$ kgs. were taken.

2. Features of RDS I) Tachypnoea ii) Grunting iii) Increase oxygen demand iv) Radiographic findings.

\section{Exclusion Criteria}

1. Neonates with APGAR score $<2$ at 5 min.

2. Congenital malformations

3. Pneumonia \& incompletely treated pneumothorax.

4. Babies diagnosed with meconium aspiration syndrome.

All babies, both inborn \& out born, admitted to NICU with gestational age $<35$ weeks and $<1.5 \mathrm{kgs}$ with RDS by clinical Silverman - Anderson scoring, Score $10=$ Severe respiratory distress Score $\geq 7$ = Impending respiratory failure, Score $0=$ No Respiratory distress. The Silverman Andersen ${ }^{8}$ Respiratory Severity Score is an easy, quick, non-invasive method to assess new-born respiratory distress with a long history of use in many low-resource settings to guide therapy. From Silverman, W. and Anderson, D.: Paediatrics 17:1, 1956. American Academy of Paediatrics. and radiographic criteria and requiring supplemental oxygen by NCPAP, or by oxygen hood were taken. RDS was defined as clinical respiratory distress in the presence of chest X-ray evidence of lung field granularity, small lung volumes and air bronchogram. 


\section{Statistical Analysis}

Descriptive and inferential statistical analysis has been carried out in the present study. Results on continuous measurements are presented on Mean \pm SD (Min-Max) and results on categorical measurements are presented in number (\%). Significance is assessed at $5 \%$ level of significance. Student $t$ test (two tailed, independent) has been used to find the significance of study parameters on continuous scale between two groups (Inter group analysis) on metric parameters. Chi-square/ Fisher Exact test has been used to find the significance of study parameters on categorical scale between two or more groups.

\section{RESULTS}

A total of 100 infants were included in the study. Of them 50 surfactant, 50 non-surfactant was taken. The study groups were similar with regard to baseline characteristics.

\begin{tabular}{|ccccc|}
\hline $\begin{array}{c}\text { Gestational } \\
\text { Age }\end{array}$ & \multicolumn{2}{c|}{ Non-surfactant } & \multicolumn{2}{c|}{ Non-surfactant } \\
$27-29$ & No & $\mathbf{\%}$ & No & $\%$ \\
$30-32$ & 12 & 25.0 & 10 & 19.4 \\
$32-35$ & 34 & 66.6 & 37 & 75.0 \\
Total & 4 & 8.33 & 3 & 5.55 \\
\multicolumn{4}{c}{ Table 1. Gestational Age } & in Two Groups Studied \\
\hline & 50 & 100 & 50 & 100.0 \\
\hline $\mathrm{P}=0.65$ (Not significant) &
\end{tabular}

In two groups most of the babies are 30-32 weeks, gestational age $66.6 \%$, and $75 \%$ in surfactant and nonsurfactant groups respectively.

\begin{tabular}{|c|c|c|c|c|c|c|}
\hline & \multicolumn{4}{|c|}{ Surfactant } & \multirow{2}{*}{\multicolumn{2}{|c|}{ Non-surfactant }} \\
\hline & \multicolumn{2}{|c|}{ Insure Success } & \multicolumn{2}{|c|}{ Insure Failure } & & \\
\hline & No & $\%$ & No & $\%$ & No & $\%$ \\
\hline ELBW & 4 & 16.6 & 7 & 27.7 & 9 & 16.7 \\
\hline VLBW & 21 & 83.3 & 18 & 72.2 & 41 & 83.3 \\
\hline & \multicolumn{4}{|c|}{$\begin{array}{c}\text { Mean } \pm S D=1.30 \pm 0.20 \text { Mean } \pm S D=1.19 \pm 0.20 \\
P=0.01^{*}\end{array}$} & \multicolumn{2}{|c|}{$\begin{array}{c}\text { Mean } \pm \mathrm{SD}=1.22 \pm 0.17 \\
\mathrm{P}=0.59\end{array}$} \\
\hline \multicolumn{7}{|c|}{ Table-2. ELBW/VLBW in Two Groups Studied } \\
\hline
\end{tabular}

The mean weight in the INSURE success and the failure group were $1.30 \pm 0.20 \& 1.19 \pm 0.20$ respectively with $\mathrm{P}=0.01$ is statistically significant. The non-surfactant group does not show any significant difference with the mean weight being $1.22 \pm 0.17$. More the birth weight better is the INSURE outcome.

In our study males constituted more both in surfactant group and non-surfactant group. 35(69.4\%) in surfactant group and $30(61.1 \%)$ in non-surfactant group were males.

The place of delivery did not show any statistical difference between the surfactant group and the nonsurfactant group. Almost $25(50 \%)$ in the surfactant group and $21(41.7 \%)$ in the non-surfactant group were delivered in our hospital. 25(50\%) in surfactant group and 29 (58.3\%) in non-surfactant group were extramural like PHC, home delivery or private hospital.

\begin{tabular}{|c|c|c|c|c|c|c|}
\hline \multirow{3}{*}{ Score } & \multicolumn{4}{|c|}{ Surfactant } & \multirow{2}{*}{\multicolumn{2}{|c|}{ Non-surfactant }} \\
\hline & \multicolumn{2}{|c|}{ Insure Success (25) } & \multicolumn{2}{|c|}{ Insure Failure (25) } & & \\
\hline & No. & $\%$ & No. & $\%$ & No & $\%$ \\
\hline $1-3$ & 6 & 22.2 & 3 & 11.1 & 0 & 0 \\
\hline $4-6$ & 18 & 72.2 & 16 & 66.6 & 38 & 75 \\
\hline \multirow[t]{3}{*}{$7-10$} & 1 & 5.55 & 6 & 22.2 & 12 & 25 \\
\hline & Mear & $4.50 \pm 1.1$ & Mean \pm & $5.44 \pm 1.1$ & & \\
\hline & \multicolumn{4}{|c|}{ Mean $\pm \mathrm{SD}=5.63 \pm 1.19$} & \multicolumn{2}{|c|}{$\begin{array}{c}\text { Mean } \pm \mathrm{SD}= \\
6.57 \pm 1.34\end{array}$} \\
\hline Total & \multicolumn{4}{|c|}{$P=0.009 * *$} & \multicolumn{2}{|c|}{$P=0.006^{* *}$} \\
\hline & \multicolumn{6}{|c|}{ Table 3. Silverman - Anderson Score in Two Groups } \\
\hline
\end{tabular}

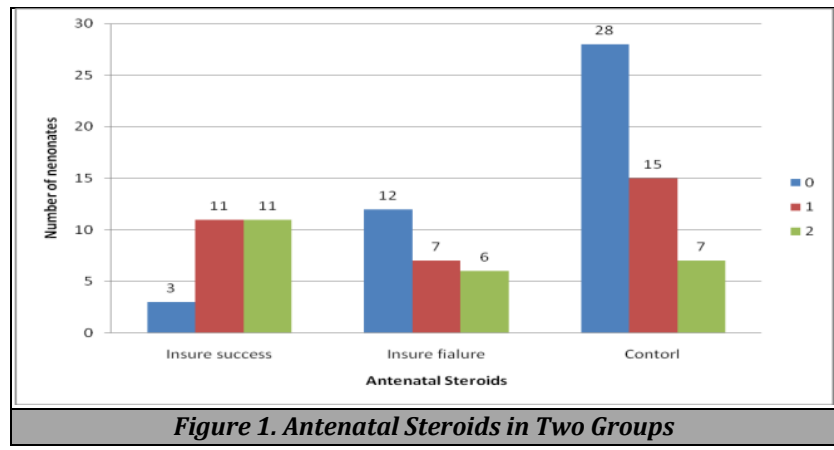

$\mathrm{P}$ is significant, Fischer exact test (1-3 mild, 4-6 moderate, 7-10 severe). All the neonates (surfactant \& non-surfactant group) needed $\mathrm{CPAP}^{9,10}$ at the time of admission. The cases received surfactant, in which 47 (94.4\%) \& 3 (5.6\%) received one and two doses 6 respectively. out of 50 neonates $25(50 \%)$ of neonates needed MV in study group while 36 $(72.3 \%)$ in control group required $\mathrm{MV}^{11}$ which is statistically significant. The duration of MV is more in the non-surfactant group then the surfactant group. $30(61.1 \%)$ in the control group required MV even after 4 days whereas $2(2.77 \%)$ in the surfactant group were on ventilator which is statistically significant.
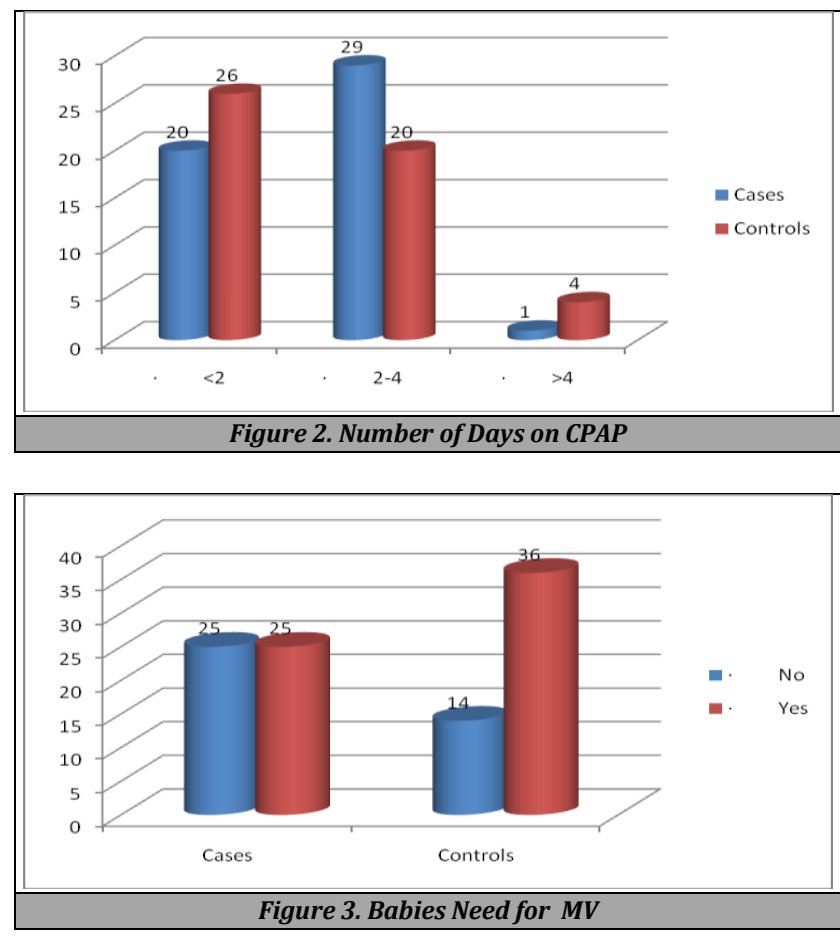

\begin{tabular}{|ccccc|}
\hline Need for & \multicolumn{2}{c}{ Surfactant } & \multicolumn{2}{c|}{ Non-surfactant } \\
MV & No & $\mathbf{\%}$ & No & \% \\
YES & 25 & 50.0 & 36 & 72.2 \\
NO & 25 & 50.0 & 14 & 27.7 \\
Total & 50 & 100.0 & 50 & 100.0 \\
\hline \multicolumn{3}{|c|}{ Table 4. Subsequent Ventilation } \\
\hline P=0.053+, significant, chi-square test \\
\hline
\end{tabular}

The primary outcome in the study group is the need for the subsequent ventilation. $25(50 \%)$ in the surfactant group required MV \& $36(72.3 \%)$ in the control group required MV. The use of surfactant decreased the need for MV by $22 \%$ in study group than control group. Surfactant replacement therapy ${ }^{12}$ at birth, final analysis of a clinical trial and comparisons with similar trials, 21 (41.7\%) in the surfactant 
group \& $27(55.5 \%)$ in the non-surfactant group showed mortality.

In the group, the time at which the procedure is performed had relation with its recovery, mortality, and the need for MV. Out of 50 neonates in surfactant group 21 cases were given surfactant within 2 hrs of age in whom 17 cases recovered and 5 required MV among whom 4 cases expired. 36 neonates of surfactant group received the dose between 2 $6 \mathrm{hr}$ of age in whom only 12 cases recovered and 17 needed MV among whom 14 cases expired. In 2 cases who received surfactant dose $>6 \mathrm{hrs}$, none survived.

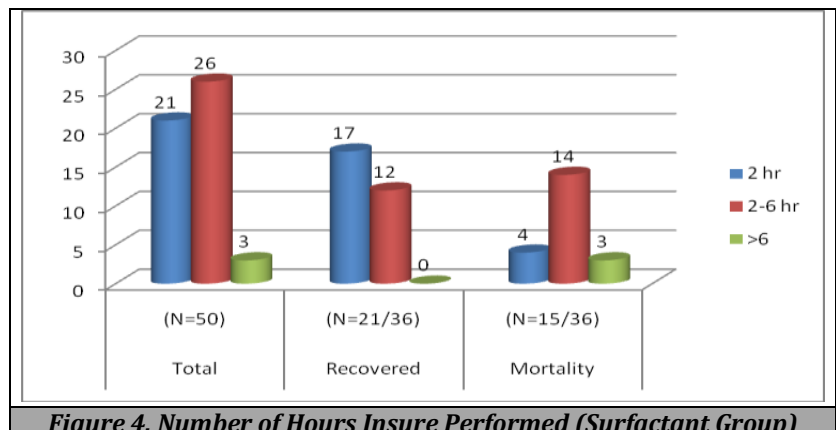

Figure 4. Number of Hours Insure Performed (Surfactant Group)

\begin{tabular}{|ccccc|}
\hline \multicolumn{4}{c}{ Surfactant Group } & \multicolumn{2}{c|}{ Non-surfactant Group } \\
a/A ratio & Pre surfactant Post surfactant & Pre ventilation & Post ventilation \\
$($ Mean \pm SD) & $0 . .21 \pm 0.06$ & $0.33 \pm 0.09$ & $0.25 \pm 0.08$ & $0.23 \pm 0.09$ \\
& \multicolumn{2}{c}{$\mathrm{P}=0.0001$} & $* * *$ \\
\hline
\end{tabular}

The mean value of the a/A ratio in the surfactant group were $0.21 \pm 0.06$ in pre surfactant group and $0.33 \pm 0.09$ in post surfactant group. ( $\mathrm{p}=0.0001^{* *}$ ). In the control group the ratio is $0.25 \pm 0.08$ in pre ventilation group and $0.23 \pm 0.09$ in post ventilation group. There is a significant increase in the oxygenation in the surfactant group compared to control group after the intervention

\begin{tabular}{|ccc|}
\hline & $\begin{array}{c}\text { Early Surfactant } \\
(<2 / 2 \mathbf{h r s}) \text { Mean } \pm \text { SD }\end{array}$ & $\begin{array}{c}\text { Late Surfactant ( }>\text { 2hrs) } \\
\text { Mean } \pm \text { SD }\end{array}$ \\
Pre surfactant a/A ratio & $0.25 \pm 0.05$ & $0.18 \pm 0.06$ \\
Post surfactant a/A ratio & $0.38 \pm 0.08$ & $0.30 \pm 0.08$ \\
\hline P value & $0.003^{*}$ & $0.007^{*}$ \\
\hline Table 6. Surfactant Oxygenation in Early vs Late Administration \\
\hline
\end{tabular}

The mean post surfactant a/A ratio in the early surfactant is $0.38 \pm 0.08$ \& late surfactant is $0.30 \pm 0.08$ which is significant. There were immediate changes in lung compliance following natural surfactant administration in premature infants with respiratory distress syndrome.

\section{DISCUSSION}

In our study the mean gestational age, mean \pm SD is $30.36 \pm 1.96$ for cases and $30.56 \pm 1.73$ for controls. Our study showed mean weight of $1300 \pm 200$ gm in surfactant group and $1220 \pm 100 \mathrm{gm}$ in control group. This is in comparison with two other studies like Rojas ${ }^{13}$ et al. $1299 \pm 325$ \& $1293 \pm 324$ for cases and controls, Verder et al. 1380 (7402915) \& 1303 (740-2860) for cases and controls respectively. The gestational age considered is between $27-31$ wks and 2535 weeks which is similar to our study. Other studies took gestational age of $<30 \mathrm{wks}$ and ELBW babies.
The mean weight in the INSURE success and the failure group were $1.30 \pm 0.20 \& 1.19 \pm 0.20$ respectively with $\mathrm{P}=0.01$ is statistically significant. The non-surfactant group does not show any significant difference with the mean weight being $1.22 \pm 0.17$. More the birth weight better is the INSURE outcome.

In Manizheh, Mostafa, Gharehbaghi et al. who studied the risk factors contributing to surfactant failure also showed that lower the birth weight more the chances of surfactant failure being $1688 \pm 472$.gm \& $1342 \pm 545 \mathrm{gm}$. for success and failure respectively.

In our study we got a good outcome for the neonates who received antenatal steroids, no difference was found whether one or two doses.

The RDS scoring in our study in the INSURE success group is less than the failure group in comparison with Manizheh ${ }^{14}$ et al. study were it is $7.1 \pm 1.3 \& 8.8 \pm 1.0$ in success and failure groups. The neonates admitted to our NICU had less scoring compared to other study.

In our study there is $22.2 \%$ decrease in the need for MV in surfactant group compared to control group. This is in comparison with other studies like Reininger et al. $20 \%$, Bohlin ${ }^{14}$ et al. $19 \%$, Rojas et al. $13 \%$. All studies conclude that the use of surfactant decrease the need for subsequent ventilation thereby preventing secondary surfactant deficiency, the present study of Verder ${ }^{15} 1994$ Verder $\mathrm{H}$, Robertson surfactant therapy and nasal continuous positive airway pressure for new-borns with respiratory distress syndrome reduced the cost of treatment.

The mortality in our study is very high when compared to other studies because of delay in the intervention. Many of the patients are extramural, came late to the hospital, financial issues, delay in the consent from the parents regarding the surfactant administration, most of the patients are illiterates and belong to lower socioeconomic status.

In our study early surfactant had low mortality when compared to late surfactant administration compared to Verder et al. study it is $9 \%$ \& $26 \%$ respectively.

The oxygenation is calculated by the a/A ratio. The a/A ratio is increased in surfactant group after administration than the control group in our study and Reininger et al. study. The increase in oxygenation in early surfactant group is more when compared to late surfactant group in our study and Verder et al. study.

The duration of MV if needed in surfactant group even after $4^{\text {th }}$ day is $1(2.1 \%)$ in our study group and $22(61.1 \%)$ in control group. In comparison with Nayeri et al. study it is 5 $(23.8 \%) \& 14(66.7 \%)$ in cases and controls respectively.

The mean total length of stay in the hospital in our study is $10.00 \pm 7.63 \& 10.83 \pm 4.59$ between surfactant and control group. But the stay in NICU requiring intensive care is $7.00 \pm 3.86$ \& $8.83 \pm 2.75$ respectively and is statistically significant. Pfister ${ }^{16} \mathrm{RH}$, Soll RF. Initial respiratory support of preterm infants: the role of CPAP, the INSURE method, and non-invasive ventilation, reduces the overall outcome of neonates from RDS.

The total length of duration in the hospital is almost similar in both the groups. The reason being other than the respiratory problem in the surfactant group like NEC, and feeding problems. Ventilator-associated pneumonia in extremely preterm neonates in a neonatal intensive care unit: Characteristics, risk factors, and outcomes. Apisarnthanarak ${ }^{17}$ 
A., Holzmann-Pazgal G., Hamvas A., Olsen M. A., \& Fraser V. J. (2003) Paediatrics, 112(6), 1283-1289. But the patients requiring the intensive care is less which may lessen the cost and make it as a cost-effective treatment.

\section{CONCLUSIONS}

1. Out of 50 neonates who received surfactant $11(22.2 \%)$ showed apnoea and 10(19.4\%) in the control group showed apnoea. The most common cause of death is pulmonary haemorrhage, $28 \%$ in surfactant group whereas $20 \%$ in control group.

2. The patients requiring the intensive care is less in the surfactant group compared to control group with the mean stay of $7.00 \pm 3.86 \& 8.83 \pm 2.75$ in surfactant and control group respectively and is statistically significant.

3. This study concludes that among spontaneously breathing premature infants treated with INSURE, decreases the need for subsequent MV by $22 \%$.

4. The higher birth weight, the use of antenatal steroids, the lower RDS score at the time of procedure and the early use of surfactant as the good predictors in the INSURE success group.

5. There is a significant decrease in the need for MV in the surfactant group compared to control group.

6. The reduction in the need for MV decreased the risk of air leak syndrome and is advantageous in medical settings where resources are limited like in our country.

7. The shorter requirement of respiratory support contributes to the decreasing stay in the intensive care unit which can be attributed as a cost-effective treatment.

Data sharing statement provided by the authors is available with the full text of this article at jemds.com.

Financial or other competing interests: None.

Disclosure forms provided by the authors are available with the full text of this article at jemds.com.

\section{REFERENCES}

[1] Halliday HL. Recent clinical trials of surfactant treatment for neonates. Biol Neonate 2006;89(4):323-9.

[2] Enhorning G, Shennan A, Possmayer F. Prevention of neonatal respiratory distress syndrome by tracheal instillation of surfactant: a randomised clinical trial. Paediatrics 1985;76(2):145-53.

[3] Sandri F, Plavka R, Ancora G, et al. Prophylactic or early selective surfactant combined with nCPAP in very preterm infants. Pediatrics 2010;125(6):e1402-9.

[4] Rojas-Reyes MX, Morley CJ, Soll R. Prophylactic versus selective use of surfactant in preventing morbidity and mortality in preterm infants. Cochrane Database Syst Rev 2012;3:CD000510.
[5] Soll R, Ozek E. Multiple versus single doses of exogenous surfactant for the prevention or treatment of neonatal respiratory distress syndrome. Cochrane Database Syst Rev 2009;1:CD000141.

[6] Dani C, Bertini G, Pezzati M, et al. Early extubation and nasal continuous positive airway pressure after surfactant treatment for respiratory distress syndrome among preterm infants $<30$ weeks' gestation. Pediatrics 2004;113(6):560-3.

[7] Kendig JW, Notter RH, Cox C. Surfactant replacement therapy at birth: final analysis of a clinical trial and comparisons with similar trials. Paediatrics 1988;82(5):756-62.

[8] Gopel W, Kribs A, Ziegler A, et al. Avoidance of mechanical ventilation by surfactant treatment of spontaneously breathing preterm infants (AMV): an open-label, randomised, controlled trial. Lancet 2011;378(9803):1627-34.

[9] Rojas MA, Lozano JM, Rojas MX, et al. Very early surfactant without mandatory ventilation in premature infants treated with early continuous positive airway pressure: a randomized, controlled trial. Pediatrics 2009;123(1):137-42.

[10] Oncel MY, Arayici S, Uras N, et al. Nasal continuous positive airway pressure versus nasal intermittent positive-pressure ventilation within the minimally invasive surfactant therapy approach inpreterm infants: a randomised controlled trial. Arch Dis Child Fetal Neonatal Ed 2016;101(4):f323-8.

[11] Schmölzer GM, Kumar M, Pichler G, et al. Non-invasive versus invasive respiratory support in preterm infants at birth: systematic review and meta-analysis. BMJ 2013;347:f5980.

[12] Jobe AH, Mitchell BR, Gunkel JH. Beneficial effects of the combined use of prenatal corticosteroids and postnatal surfactant on preterm infants. Am J Obstet Gynecol 1993;168(2):508-13.

[13] Merritt TA, Hallman M, Bloom BT, et al. Prophylactic treatment of very premature infants with human surfactant. N Engl J Med 1986;315(13):785-90.

[14] Bohlin K, Gudmundsdottir T, Katz-Salamon M, et al. Implementation of surfactant treatment during continuous positive airway pressure. J Perinatol 2007;27(7):422-7.

[15] Verder H, Robertson B, Greisen G, et al. Surfactant therapy and nasal continuous positive airway pressure for newborns with respiratory distress syndrome. N Engl J Med 1994;331(16):1051-5.

[16] Pfister RH, Soll RF. Initial respiratory support of preterm infants: the role of CPAP, the INSURE method, and noninvasive ventilation. Clin Perinatol 2012;39(3):45981.

[17] Apisarnthanarak A, Holzmann-Pazgal G, Hamvas A, et al. Ventilator-associated pneumonia in extremely preterm neonates in a neonatal intensive care unit: characteristics, risk factors, and outcomes. Pediatrics 2003;112(6 Pt 1):1283-9. 